\title{
New materials development utilizing mechanochemical synthesis
}

\author{
P. Q. H. Nguyen ${ }^{1}$, W. McKenzie ${ }^{1}$, D. Zhang ${ }^{1,2}$, J. Xu ${ }^{1,2}$, R. Rapp ${ }^{1}$, J. P. Bradley ${ }^{1}$, P. Dera ${ }^{1}$ \\ ${ }^{1}$ Hawai'i Institute of Geophysics and Planetology, University of Hawai'i at Manoa, Honolulu, Hawai'i 96822, USA \\ ${ }^{2}$ GeoSoiEnviro CARS, Argonne National Laboratory, University of Chicago, Argonne, Illinois 60439, USA \\ nguyenph@hawaii.edu
}

The past few decades have witnessed mechanochemistry emerging at the forefront of solid-state chemical synthesis, driven by the search of new and cleaner synthetic methodologies. Mechanochemical synthesis utilizes high energy impact phenomenon to initiate chemical reactions. The peak impact pressures, which the individual sample particles experience, vary depending on the type of mill, milling speed, as well as size, shape, and density of the milling components, but can often exceed $10 \mathrm{GPa}$, while the temperature remains below $100{ }^{\circ} \mathrm{C}$. Evolving beyond simply a solvent-free alternative, mechanochemistry offers significant sample quantities (grams) processed over a short period of time (minutes to hours). The design of the mill (e.g. tumbler, oscillatory, planetary) can also control the relative contributions of friction and impact during the milling process. In an effort to introduce mechanochemistry further into geoscience, the current presentation wishes to showcase the successful mechanochemical synthesis of compounds in the Mg-Co olivine solid solution series (e.g. $\mathrm{Mg}_{2} \mathrm{SiO}_{4}, \mathrm{MgCoSiO}_{4}, \mathrm{Co}_{2} \mathrm{SiO}_{4}$ ) starting from simple oxide precursors such as $\mathrm{MgO}, \mathrm{CoO}$, and $\mathrm{SiO}_{2}$ utilizing oscillating mill equipped with tungsten carbide (WC) jars/ balls as reaction vessels [1,2]. We further address on the contamination issue of the final synthesized product with debris shaved off from milling media (e.g. stainless steel, WC) and report on a successful development of method for converting WC to a water-soluble form [3]. Lastly, we report our investigations into pressureinduced phase transformation of anatase $\mathrm{TiO}_{2}$ to rutile $\mathrm{TiO}_{2}$, quartz-type $\alpha-\mathrm{GeO}_{2}$ to rutile $\mathrm{GeO}_{2}$, and cubic $\mathrm{Dy}_{2} \mathrm{O}_{3}$ to monoclinic $\mathrm{Dy}_{2} \mathrm{O}_{3}$, processes that require pressure up to $7.7 \mathrm{GPa}$ in a typical diamond anvil cell experiment [4]. Powder X-Ray Diffraction was employed as the main process characterization, with complete Rietveld refinements of the powder patterns of end products, where applicable.

[1] Nguyen, P. Q. H, Zhang, D., Rapp, R., Bradley, J. P., Dera, P. (2021). RSC Adv. 11, 20687.

[2] Nguyen, P. Q. H., McKenzie, W., Zhang, D., Xu, J.; Rapp, R., Bradley, J. P., Dera, P. submitted

[3] Nguyen, P. Q. H., McKenzie, W., Zhang, D., Xu, J., Dera, P. submitted

[4] Nguyen, P. Q. H., Dera, P. submitted

Keywords: Impact energy; Mechanochemical synthesis; Phase transformation; Mill

This work was performed with the financial support provided by the Office of Naval Research, Department of Navy's Historically Black Colleges and Universities/Minority Institutions, the Materials for Thermal and Chemical Extreme program, grant number FOA N00014-19-S-F004. 